\title{
THE BUDGET ALLOCATION MODEL OF PUBLIC INFRASTRUCTURE PROJECTS
}

\author{
Wen-Chih Huang \\ Department of Transportation Technology and Management, Kainan University, Taoyuan County, Taiwan, R.O.C \\ Junn-Yuan Teng \\ Department of Industrial Engineering and Management Information, Huafan University, Taiwan, R.O.C. \\ Maw-Cherng Lin \\ Department of Harbor and River Engineering, National Taiwan Ocean University, Taiwan, R.O.C, \\ f5041284@trts.dorts.gov.tw
}

Follow this and additional works at: https://jmstt.ntou.edu.tw/journal

Part of the Business Commons

\section{Recommended Citation}

Huang, Wen-Chih; Teng, Junn-Yuan; and Lin, Maw-Cherng (2010) "THE BUDGET ALLOCATION MODEL OF PUBLIC INFRASTRUCTURE PROJECTS," Journal of Marine Science and Technology. Vol. 18: Iss. 5, Article 10.

DOI: 10.51400/2709-6998.1917

Available at: https://jmstt.ntou.edu.tw/journal/vol18/iss5/10

This Research Article is brought to you for free and open access by Journal of Marine Science and Technology. It has been accepted for inclusion in Journal of Marine Science and Technology by an authorized editor of Journal of Marine Science and Technology. 


\section{THE BUDGET ALLOCATION MODEL OF PUBLIC INFRASTRUCTURE PROJECTS}

\section{Acknowledgements}

The authors would like to express their gratitude for the detailed attention and valuable feedback from the referees, and the suggestions and encouragement from the Editor during the review period. 


\title{
THE BUDGET ALLOCATION MODEL OF PUBLIC INFRASTRUCTURE PROJECTS
}

\author{
Wen-Chih Huang*, Junn-Yuan Teng**, and Maw-Cherng Lin***
}

Key words: budget allocation, public infrastructure projects, fuzzy MCDM.

\begin{abstract}
One of the most important problems for governments is how to allocate budgets for public infrastructure projects. This question becomes especially important during periods of financial difficulties. The budget allocation model of public infrastructure projects proposed in this paper integrates 3 submodels: the fuzzy multi-criteria grade classification model; the fuzzy multi-criteria project ranking model; and the budget allocation model. This integrated model promises to allocate simultaneously the budget of public infrastructure projects and decide the construction budget for each unit. This budget allocation mode allows for ready reactions to changes of budget policies. It moreover, factors for discretionary budgets given to senior managers. Via this model, managers can significant ly improve management efficiency and take corresponding personal responsibility.
\end{abstract}

\section{INTRODUCTION}

As substantial programs promoted by the government, public infrastructure projects aim to improve standards of living and enhance economic development by providing the facilities and equipment necessary for social use, security and well-being. The budget is the fiscal income and expense plan for a certain period. It is determined by properly assessing resources and affordability. Resources are allocated via political procedures. Policies must be executed through budgets. In this way, public infrastructure projects can be legally implemented and realized via the budget system, exclusive of self-liquidating projects.

Public infrastructure projects are closely linked to the lives of citizens. Major tasks in public infrastructure projects include: effective allocation; putting the budget to the best use;

Paper submitted 02/13/09; revised 09/16/09; accepted 09/17/09. Author for correspondence: Maw-Cherng Lin (e-mail: f5041284@trts.dorts.gov.tw).

*Department of Transportation Technology and Management, Kainan University, Taoyuan County, Taiwan, R.O.C.

**Department of Industrial Engineering and Management Information, Huafan University, Taiwan, R.O.C.

***Department of Harbor and River Engineering, National Taiwan Ocean University, Taiwan, R.O.C. and maximizing the function of a limited budget. But it is difficult to realize effective budget allocations because related units make competing claims for funding. In most cases, egalitarian allocation and allocation based on the size of both the population of units and the region they govern are utilized by policy makers. These methods may result in poor distribution, in which, for example, a "squeaky wheel gets the grease," while less powerful or more compliant units receive less than their shares. However, budget allocation is designed principally to make the most effective use of resources by allocating resources to where they are most needed.

The selection of public infrastructure allocation typically consists of multi-objectives, multi-attributes and multi-criteria. The demands of society, the economy, finance, human resources, the environment, markets, and politics influence decisions. Due to their potential to clash and their variability, comparability and correlation, various criteria shall be evaluated and selected using a Multiple Criteria Decision-Making Method (MCDM). This method supplants the widely used CostBenefit Analysis (CBA) or Single-objective Mathematical Programming method. Bellmen and Zadeh [5] pioneered the exploration of decision-making in a fuzzy environment. Baas and Kwakernaak [3] propose to use preferred fuzzy sets as the method of ranking alternatives. There are many methods for implementing a fuzzy MCDM. For example, Chen and Hwang [8] make a distinction and classification for each method using fuzzy ranking and fuzzy multiple attribute decision-making methods. Buckley [7] offers the Fuzzy Analytic Hierarchy Process method (Fuzzy AHP), which fuzzes the paired comparison values in Saaty's AHP method and works out the fuzzy weights of each evaluation dimension and evaluation criterion with a geometric mean method; it mainly aims at structuring problems and simplifying complex problems via hierarchical structures; it also uses different fuzzy numbers to represent the ideas of experts [15].

Much research is in progress to probe into the application of the MCDM, evaluation and selection alternatives. These include: selecting the location of a regional hospital [33], analyzing the competitive relations of a global logistics hub [19], establishing an electric power energy development program [31], appraising transportation construction planning [27], evaluating sightseeing risk factors [30], and assessing industry marketing strategies [26, 29]. This method is combined by Cook [9] with an analysis of hierarchical procedures and time 
series in an urban configuration model. It has been utilized by Pearman et al. [22] to rank road investment programming. An AHP method has been utilized by Azis [2] to evaluate the influence of constructing an expressway and by McIntyre and Parfitt [21] to explore land development site decisions and the selections of contractors or procurement methods $[1,11,20]$. Kwak and Diminnie [18] have resorted to a goal programming model to research the budget allocation of academic units; Ramanathan et al. [24] and Belenky [4] apply the AHP method or using dynamic process of data improvement to resource allocation; Johnstone [16] use portfolio theory and the capital asset pricing model applies to the valuation of probability forecasts; Perng et al. [23] use the Genetic Algorithm (GA) to solve budget allocation problems in the restoration of historical buildings; Han et al. [13] adopt a non-linear programming model to determine the optimal financial budget for software development plans; Karydas and Gifun [17] apply a multi-attribute utility theory to the budget allocation of the infrastructure renewal programs on university campuses. In these studies, fuzzy MCDM is applied to unquantifiable or nonqualitative evaluation projects, except budget allocation, to select and rank alternatives; it has yielded the required results.

This paper explores systematical budget allocation of public infrastructure projects, making modifications according to current practice in Taiwan. In view of the demands of decision-making, we adopt fuzzy sets theory and selection criteria for public infrastructure projects to construct a fuzzy multi-criteria grade classification model which will help classify public infrastructure projects into several grades in accordance with their priorities of needs. Additionally, this paper proposes a fuzzy multi-criteria project ranking model for the selection of public infrastructure projects to select out nonurgent projects. Lastly, this paper integrates the fuzzy multicriteria grade classification model, the fuzzy multi-criteria project ranking model, and the budget allocation model to construct a complete model for the budget allocation of public infrastructure projects.

\section{SYSTEMATICAL BUDGET ALLOCATION FOR PUBLIC INFRASTRUCTURE PROJECTS}

Without objective methods the selection of public infrastructure projects results in too much authority interference; moreover, the methodology will vary from person to person, potentially affecting the continuity and stability of public infrastructure projects and allowing insufficient allocation to projects in real want of funding. The budget allocation of public infrastructure projects must be objective and also take the operation of existing organizational systems into account. Based on this viewpoint, this study proposes a systematical budget allocation for public infrastructure projects. Figure 1 shows the basis of model construction.

The top layer represents the available funds that the ministry of communications can use or manage. These funds may be reduced due to policy changes from the legislature. The

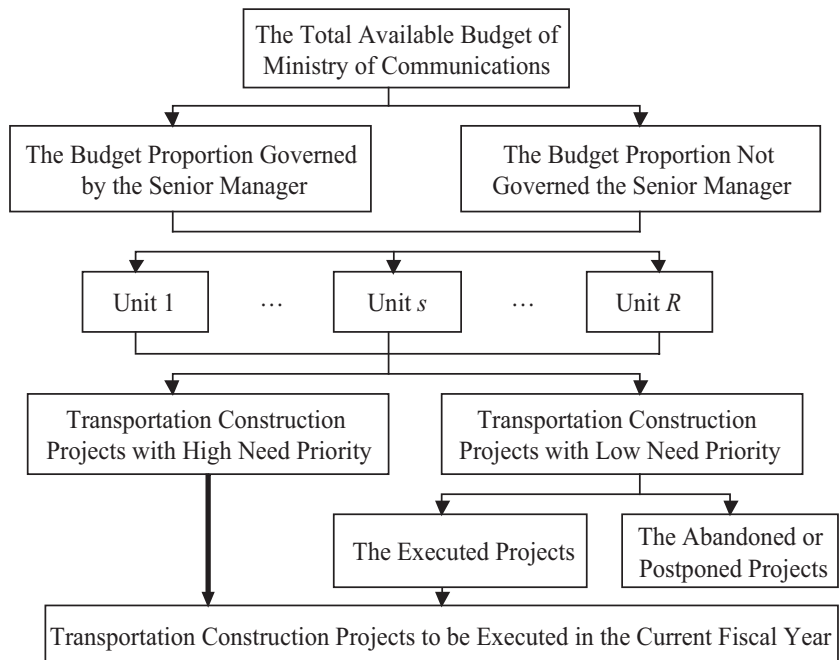

Fig. 1. The systematical concept chart of the budget allocation of transportation construction projects.

deletion of projects or funds is a difficult subject. According to current practice, continuing projects will be continued as far as possible and the others will be deleted. In practice, this has caused construction projects to be carried out piecemeal. The failure to bring into full play the efficiency of these projects leads to criticism from citizens. Traditionally, the senior manager in the ministry has been granted the right to determine executable projects; as far as the function of management is concerned, this right is indispensable, but it must be factored into the model of allocation.

In the appraisal of construction projects, one major difficulty rests with the fact that the related projects are huge in number and come from different professional fields and implementation units. Among the construction projects from each unit, some are continuing projects that must be given priority in execution, but others are ordinary projects newly proposed or with low priority. The continuing projects that must be dealt with first ought to have the budget in principle, exclusive of those with low execution performances in the previous fiscal year. Thus, it is possible to obtain the expected results and execute the government's policies. Suspension of projects can be avoided. The means by which the newlyproposed projects or those with low priority receive allocations depend on how much balance of the total budget remains after the demands priority projects have been satisfied. If the balance cannot meet their needs, the former should be evaluated and selected according to their priorities; the projects in urgent need of money could be executed first and the others may be abandoned or postponed.

If the above budgets are put down by the legislative branches or if they have to be cut for any reason, all public infrastructure projects will surely be affected. So, these projects need to be deleted according to the order of priorities constituted in the original objective model; the projects that remain after deletion are those that must be executed in the present fiscal year. 
From this systematical concept chart of the budget allocation model, some key questions must be discussed. For example, How can the budget proportion be reasonable and be used by the senior manage at the first layer? How can the projects with the budget that can be controlled by the manager at the second layer be evaluated and selected? How should the priorities of projects be appraised? The budget proportion that can be used by the senior manager ought to be determined in accordance with policies, and the rest is resolved by the proposed budget allocation model.

\section{FUZZY MULTI-CRITERIA GRADE CLASSIFICATION MODEL}

The first task in the budget allocation for public infrastructure construction is to determine the priority of execution among public infrastructure projects. The fuzzy multicriteria grade classification model [28] put forward by this study is able to effectively deal with the need priorities of public infrastructure projects. The projects at high need priority level will be given the budget first; those at low need priority level can be implemented, depending on how much of the budget is left.

The following are the theoretical methods and procedures of Fuzzy MCDM, applied in this paper.

Step 1: List all infrastructure plans to be evaluated

List $n$ public infrastructure plans: $A=\left\{A_{1}, \ldots, A_{i}, \ldots, A_{n}\right\}$ $(n \geq 1)$.

Step 2: Formulate evaluation criteria

Formulate $m$ evaluation criteria: $C=\left\{C_{1}, \ldots, C_{j}, \ldots, C_{m}\right\}$ $(m \geq 1)$.

Step 3: Distinguish need grades

The weighing of the achieved performance under each evaluation criterion can be distinguished into $P$ need grades $V_{j}=\left\{V_{j 1}, \ldots, V_{j k}, \ldots, V_{j P}\right\}(P \geq 2)$; the grade priority tends to decrease, namely, $V_{j 1}$ indicates the most needed while $V_{j P}$ the slightly needed.

Step 4: Determine the weights of evaluation criteria

Determining the importance of $m$ evaluation criteria; the experts from the related fields can be invited to assign the corresponding weights: $\tilde{w}=\left\{\tilde{w}_{1}, \cdots, \tilde{w}_{j}, \cdots, \tilde{w}_{m}\right\}$

Step 5: Establish an evaluation matrix

In light of the judgments and weighting made by evaluation committee members, the fuzzy evaluation matrix $\tilde{R}_{i}$ for each public infrastructure project $A_{i}$ under the evaluation criteria $C_{j}$ can be formulated as follows:

$$
\tilde{R}_{i}=\left[\tilde{r}_{i j k}\right]_{m \times P}, i=1,2, \cdots, n
$$

In the formula, $\tilde{r}_{i j k}$ indicates the fuzzy performance value of $A_{i}$ at the grade of $V_{j k}$ under the evaluation criteria- $C_{j}$.

The evaluation criteria for public infrastructure projects are all qualitative and cannot be easily measured with definite numerical values; so, it is necessary to constitute the evaluation committee containing related experts; and then each committee member can make a judgment in accordance with the need grade of every infrastructure project under each evaluation criterion. Each member is allowed to check one within $P$ grades under each criterion.

Supposing that there are $Q$ members in the evaluation committee, the fuzzy performance value $\tilde{r}_{i j k}$ of each public infrastructure project at each need grade under each criterion can be obtained through the following formula.

$$
\begin{gathered}
\tilde{r}_{i j k}=\tilde{Q}_{i j k} / Q, \forall i, j, k \\
\tilde{Q}_{i j k}=\sum_{f=1}^{Q} \tilde{Q}_{i j k}^{f}, \forall i, j, k \\
\text { dicates the } f^{t h} \text { evaluation } \\
\text { Grade } k \text { under the criter } \\
\sum_{f=1}^{Q} \sum_{k=1}^{p} \tilde{Q}_{i j k}=Q \\
0 \leq \tilde{r}_{i j k} \leq 1
\end{gathered}
$$$$
\tilde{Q}_{i j k}^{f}=\left\{\begin{array}{c}
1 . \text { Indicates the } f^{\text {th }} \text { evaluation committee } \\
\text { member's judgment that } A_{i} \text { belongs } \\
\text { to Grade } k \text { under the criterion of } C_{j} . \\
0 . \text { Others. }
\end{array}\right.
$$

Step 6: Calculate the fuzzy evaluation vector after the weighting.

When considering $m$ evaluation criteria simultaneously, we can calculate the following fuzzy evaluation vector $\tilde{E}_{i}$ after the weighting.

$$
\tilde{E}_{i}=\left(\tilde{E}_{i 1}, \cdots, \tilde{E}_{i k}, \cdots, \tilde{E}_{i p}\right)=\tilde{w} \otimes \tilde{R}_{i}
$$

In the formula,

$$
\begin{gathered}
\tilde{E}_{i k}=\sum_{j=1}^{m} \tilde{w}_{j} \tilde{r}_{i j k}, k=1,2, \ldots, P \\
\sum_{k=1}^{P} \tilde{E}_{i k}=1, i=1,2, \ldots, n
\end{gathered}
$$

Step 7: Grade classification

Since $\tilde{E}_{i k}$ refers to the $A_{i}$ 's degree of membership at grade $k$ under $m$ evaluation criteria. So the priority sequence of public 
infrastructure projects is the result of the grade classification of $n$ public infrastructure projects $-A_{1}, A_{2}, \ldots, A_{n}$, with $\tilde{E}_{i 1}, \ldots \tilde{E}_{i k}, \ldots, \tilde{E}_{i P}$ known.

1. If there are only two grades classified:

(1) If there are two grades (namely, $P=2, V=\{X, Y\}$ ) classified in grade classification, and the degree of membership at grade $X$ meets the value of $\lambda$ (which is decided by the evaluation committee, for instance, $\lambda=0.5$ or $\lambda=0.7$ ), then $A_{i}$ belongs to $X$; if the degree of membership at grade $X$ fails to meet the value of $\lambda$, then $A_{i}$ belongs to $Y$.

(2) Let $\alpha_{x}$ and $\alpha_{y}$ be the degree of membership of $A_{i} \in X$ and $A_{i} \in Y$ respectively and $\alpha_{x}+\alpha_{y}=1$, then there are three possibilities:
(a) $\alpha_{x}>\lambda$, then $A_{i} \in X$;
(b) $\alpha_{x}=\lambda$, then $A_{i} \in X$ or $A_{i} \in Y$;
(c) $\alpha_{y}>\lambda$, then $A_{i} \in Y$.

2. If there are three grades classified:

If there are three grades classified $[(P=3), V=\{X, Y, Z\}]$, then:

(1) In classifying the grade of $A_{i}$, we can use $V_{1}=\{X, Y$ or $Z\}$ and $V_{2}=\{Y, Z\}$ to conduct the evaluation to obtain their respective degrees of membership $\left(\alpha_{1}, \overline{\alpha_{1}}\right)$ and $\left(\alpha_{2}, \overline{\alpha_{2}}\right)$ $\left(\alpha_{1}+\overline{\alpha_{1}}=1\right.$ and $\left.\alpha_{2}+\overline{\alpha_{2}}=1\right)$.

(2) Use the values of $\alpha_{1}$ and $\alpha_{2}$ to make grade classification:

(a) First make grade classification based on the value of $\alpha_{1}$, if:

(i) $\alpha_{1} \geq \lambda$, then $A_{i} \in X$;

(ii) $\overline{\alpha_{1}} \geq \lambda$, then $A_{i} \in Y$ or $A_{i} \in Z$;

(b) Then make grade classification based on the value of $\alpha_{2}$, if:

(i) $\alpha_{2} \geq \lambda$, then $A_{i} \in Y$

(ii) $\overline{\alpha_{2}} \geq \lambda$, then $A_{i} \in Z$

3. If there is $P$ grades classified,

(1) For $P$ evaluation grades $V=\left\{V_{1}, V_{2}, \ldots, V_{P}\right\}(P \geq 2), P-1$ evaluation sets composed of every two immediate grades can be constructed:

$$
\begin{gathered}
V_{1}^{\prime}=\left\{V_{1}, V_{2} \text { or } V_{3} \text { or } \ldots, V_{P}\right\} \\
V_{2}^{\prime}=\left\{V_{1}, V_{2} \text { or } V_{3} \text { or } \ldots, V_{P}\right\} \\
\vdots \\
V_{P-1}^{\prime}=\left\{V_{P-1}, V_{P}\right\}
\end{gathered}
$$

(2) Evaluate the same project $A_{i}$ in accordance with $V_{1}^{\prime}$, $V_{2}, \ldots, V_{P-1}^{\prime}$, and obtain the corresponding degrees of membership--- $\alpha_{1}, \alpha_{2}, \ldots, \alpha_{P-1}$.

(3) Make grade classification according to the rules shown below

(a) $\alpha_{1} \geq \lambda$, then $A_{i} \in V_{1}$; otherwise, (b) $\alpha_{2} \geq \lambda$, then $A_{i} \in V_{2}$; otherwise,

$P-1$ if $\alpha_{P-1} \geq \lambda$, then $A_{i} \in V_{P-1}$; otherwise, $A_{i} \in V_{P}$.

(4) It can be seen from the above classification logic and inferring process that the problem of grade classification will be easily resolved if the degrees of membership of $\alpha_{1}$, $\alpha_{2}, \ldots, \alpha_{P-1}$ are worked out.

Step 8: Figure out the degree of membership for the evaluation value of each grade.

1. In this paper, the inference by Hsinng \& Tsaur [28] is adopted to calculate the degree of membership for each the evaluation value of each grade. They are as follows:

$$
\begin{gathered}
\alpha_{1}=E_{i 1}=\sum_{k=1}^{1} E_{i k} \\
\alpha_{2}=\alpha_{1}+E_{i 2}=\sum_{k=1}^{2} E_{i k} \\
\alpha_{3}=\alpha_{2}+E_{i 3}=\sum_{k=1}^{3} E_{i k} \\
\vdots \\
\alpha_{p-1}=\alpha_{p-2}+E_{i(P-1)}=\sum_{k=1}^{p-1} E_{i k} \\
\alpha_{p}=\sum_{k=1}^{p} E_{i k}
\end{gathered}
$$

2. $\alpha_{1}, \alpha_{2}, \ldots, \alpha_{P}$ are the actual degrees of membership of the public infrastructure project $A_{i}$ when $A_{i}$ is evaluated at the grades $1,2, \ldots, P$; the accumulated values of $A_{i}$ 's degrees of membership at each grade are expressed through the following formula:

$$
\begin{aligned}
E_{i \Sigma} & =\left(\alpha_{1}, \alpha_{2}, \ldots, \alpha_{P}\right) \\
& =\left(\sum_{k=1}^{1} E_{i k}, \sum_{k=1}^{2} E_{i k}, \ldots, \sum_{k=1}^{P} E_{i k}\right)
\end{aligned}
$$

Step 9: Make grade classification for all infrastructure projects.

All public infrastructure projects can be classified into different grades in accordance with the degree of membership for each grade evaluation set as well as the value of $\lambda$ determined by the evaluation committee:

$$
\text { If } \alpha_{i d} \geq \lambda \text {, then } A_{i} \in V_{d}, \forall i, k
$$




$$
\text { and, } d=\min \left\{k \mid \alpha_{i k} \geq \lambda\right\}
$$

\section{THE FUZZY MULTI-CRITERIA PROJECT RANKING MODEL}

Under the formulated evaluation criteria of budget allocation, public infrastructure projects are divided into different grades according to their need priorities. By integrating all the criteria weights, provided by the evaluation members, we can know which the grade of need of each project. The projects at the first (highest) grade can be given the budget first, and if there is budget left, it will be re-allocated to those at the second grade; if the budget still remains, it will be re-distributed to those at the third grade, and so forth. When the remaining budget is insufficient for allocation to the projects at the second grade, it is necessary to evaluate and rank all the projects at this grade.

The related literature $[6,10,12,25,32]$ shows that there are many methods for the evaluation of projects, including nonnumeric and numeric models (numeric models have also consisted of quantitative models and qualitative models). The evaluation model of public infrastructure projects cannot reflect all the facts; thus, in the execution of the model time must not be wasted on unimportant details. Planners must concentrate on key points. Too many public infrastructure projects make the evaluation work more difficult, and the use of complex numeric models in evaluation and ranking of projects will certainly add to the cost. Under these circumstances, among all kinds of evaluation methods, the scoring method is most widely used because of its simplicity, low cost, and accordance with economic benefits.

When evaluating and ranking the public infrastructure projects at the same grade, we suggest to combine scoring methods with the multicriteria property to construct a fuzzy multicriteria project ranking model. Suppose there are $n_{k}$ public infrastructure projects at Grade $k$, and then under $m$ evaluation criteria $C_{j}(j=1,2, \ldots, m), Q$ evaluation members respectively carry out the individual scoring of fuzzy scale and linguistic expression for the $m$ criteria; the scope of scoring is $1,2, \ldots, S$, and the higher score indicates the more urgent need. Suppose the $f^{\text {th }}$ evaluation member scores the project $-A_{i}(i=1,2, \ldots$, $n_{k}$ ) at grade $k$ under the criterion $C_{j}$, and the result is expressed with $\tilde{s}_{i j}^{f}$, then $\tilde{A} s_{i j}$---the average score $A_{i}$ gets under the criterion $-C_{j}$ is:

$$
\tilde{A} s_{i j}=\sum_{f=1}^{Q} \tilde{s}_{i j}^{f} / Q, \forall i, j
$$

If the weights of $m$ evaluation criteria are taken into account, the average score of $A_{i}$ ' weighting at grade $k---\tilde{W} s_{i}$ is:

$$
\tilde{W} s_{i}=\sum_{j=1}^{m} \tilde{w}_{j} \otimes \tilde{A} s_{i j}, \forall i
$$

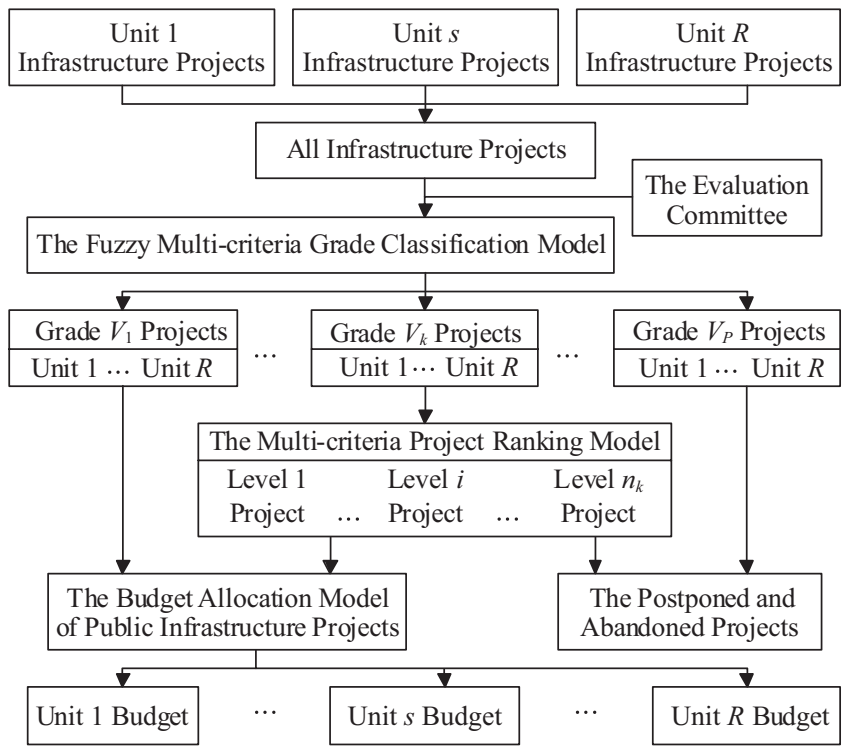

Fig. 2. The budget allocation model figure of public infrastructure projects.

Then the average score of weighting --- $\tilde{W} s_{i}$ is defuzzed, and this value can be used as the reference to rank the $n_{k}$ public infrastructure project at grade $k$ in need priority. The bigger the average value of weighting, the higher the need priority in terms of the comprehensive consideration of $m$ evaluation criteria; therefore, the project has a greater advantage in competition for funding.

\section{THE BUDGET ALLOCATION MODEL OF PUBLIC INFRASTRUCTURE PROJECTS}

The budget allocation of public infrastructure projects can be deduced according to the systematically concept chart of budget allocation in Fig. 1. Therefore, in the budget allocation model, we can further combine the fuzzy multi-criteria grade classification model, the fuzzy multi-criteria project ranking model and the multi-units (multi-fields) project expenditure allocation model, expressed in this section in Fig. 2.

Suppose there are $R$ units (or professional fields) and each unit has many public infrastructure projects; the $s^{\text {th }}$ unit $(s=1$, $2, \ldots, R)$ contains altogether $n_{s}$ public infrastructure projects, expressed as $A i_{s}\left(i_{s}=1,2, \ldots, n_{s}\right)$; hereby, $R$ units have a total of $n$ public infrastructure projects, expressed as set $A=\left\{A_{1}\right.$, $\left.A_{2}, \ldots, A_{n}\right\}$, and

$$
\begin{gathered}
A=\bigcup_{s=1}^{R} \bigcup_{i_{s}=1}^{n_{s}} A i_{s} \\
n=\sum_{s=1}^{R} n_{s}
\end{gathered}
$$

The evaluation committee, which considers the results of 


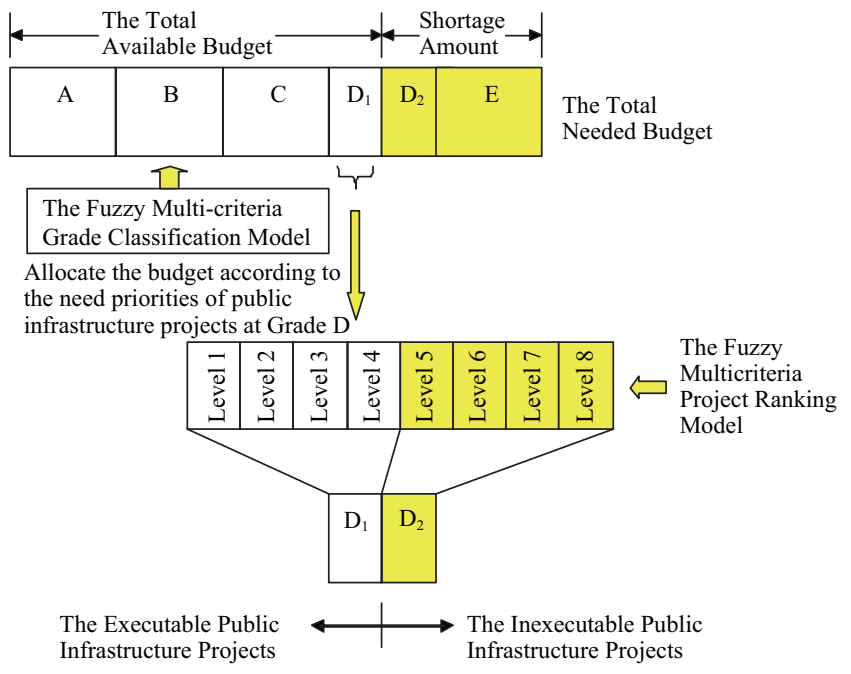

Fig. 3. The ranking and the budget allocation sketch map of public infrastructure projects at the same grade.

professional examination, judges the grade of each project for each criterion; it should, further, apply the fuzzy multi-criteria grade classification model to classify the public infrastructure projects, according as their need priorities. The projects at each grade will include the public infrastructure projects presented by each unit. In light of need priorities, public budget projects can be classified into the following five grades: "urgently needed," "greatly needed," "very needed," "fairly needed," "slightly needed" (if necessary, more sub-grades can be classified). In principle, projects in urgent want of money ought to be given first priority.

The above budget allocation methods are illustrated in Fig. 3. With the application of the fuzzy multi-criteria grade classification model, public infrastructure projects are divided into five grades, A, B, C, D, E. After the total budget is distributed to the projects at the first three grades, some funds remain that can be allocated to part of projects at grade $\mathrm{D}$. The application of the fuzzy multi-criteria project ranking model can be adopted to rank all the projects; the remaining budget can provide for the first four projects at grade D; while, the last four projects at grade D and all the projects at grade $\mathrm{E}$ will fail to be executed, due to insufficient funds.

Suppose the available budget for public infrastructure projects totals $T B$, and $B V_{k}(k=1$ represents "Urgently needed", $k=2$ "Greatly needed", $k=3$ "Very needed", $k=4$ "Fairly needed", $k=5$ "Slightly needed") refers to the budget that is needed at grade $V_{k}$; then the budget of the public infrastructure projects in each unit at this grade adds up to:

$$
B V_{k}=\sum_{s=1}^{R} \sum_{b=1}^{n_{k s}} B V_{k}\left(A_{s b}\right), k=1,2, \ldots, P
$$

In this formula, $B V_{k}\left(A_{s b}\right)$ indicates the budget needed by the public infrastructure project $-b$ in unit $s$ at grade $k ; n_{k s}$ stands for the number of public infrastructure projects in unit $s$ at grade $k ; P$ means the number of grades (here, $P=5$ means there are five grades). In $P$ grades, the summation of $n_{k s}$--- the number of infrastructure projects from all units is $n$--- the sum of all public infrastructure projects, as the following formula shows:

$$
\begin{gathered}
n=\sum_{k=1}^{P} \sum_{s=1}^{R} n_{k s} \\
n_{k}=\sum_{s=1}^{R} n_{k s}
\end{gathered}
$$

Suppose the total budget is distributed to the public infrastructure projects at grade $r(1 \leq r \geq P)$ and the remaining budget is not enough to be allocated to all the projects at grade $(r+1)$. The fuzzy multi-criteria project ranking model is utilized to rank the $\left(n_{r+1}\right)$ public infrastructure projects at grade $(r+1)$, and the surplus budget is given to the projects ranking at the top level first. The projects at grade $(r+1)$ may come from $R$ units, so those ranking at the top level and obtaining the budget may belong to different units. If the budget allocated to grade $(r+1)$ is $B_{(r+1)}$, the budget that unit $s$ may get at grade $(r+1)$ is expressed with $B_{(r+1) s}$.

The amount of budget each unit can get contain the construction expenditure of the public infrastructure projects within the previous $r$ grades and the construction expenditure of the public infrastructure projects obtaining the budget at grade $(r+1)$. If the budget given to the public infrastructure projects in Unit $s$ within $r$ grades is $R B_{s}$, then:

$$
\begin{gathered}
R B_{s}=\sum_{k=1}^{r} \sum_{b=1}^{n_{k s}} B V_{k}\left(A_{s b}\right), s=1,2, \ldots, R \\
1 \leq r \geq P
\end{gathered}
$$

Then the appraisal result indicates that the available budget of each unit total $R B_{s}(s=1,2, \ldots, R)$, as the following formula shows:

$$
E B_{s}=R B_{s}+B_{(r+1) s}, s=1,2, \ldots, R
$$

If the senior manager dominates the budget of $M B$, he or she can decide how to allocate the $M B$ to the public infrastructure projects of each unit; this should be included in the budget, as the following formula shows:

$$
B_{s}=R B_{s}+M B_{s}, s=1,2, \ldots, R
$$

Perhaps $R$ units all have the public infrastructure projects within $P$ grades; so, the budget of each unit is the accumulated budget of the executed public infrastructure projects at each grade. The budget allocation concept of each unit can be 


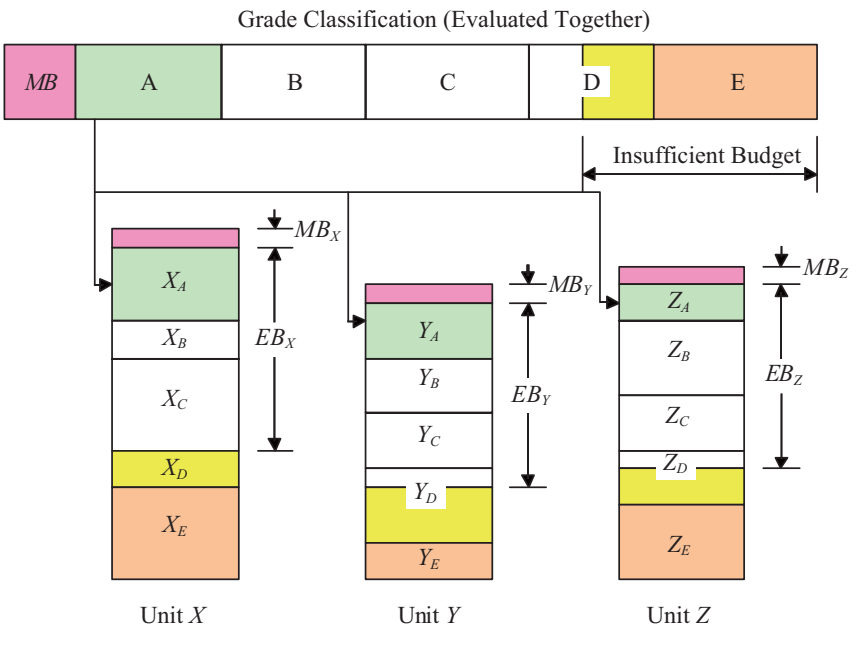

Distinctions Based on the Budget Units

Fig. 4. The budget allocation sketch map of public infrastructure projects based on units.

explained with Fig. 4. In this figure, there are three units --- $X$, $Y, Z$, and their public infrastructure projects are classified into five grades --- A, B, C, D, E in need priorities, according to the fuzzy multi-criteria grade classification model; the total budget can only be allocated to all the projects at grades $\mathrm{A}, \mathrm{B}$, and $\mathrm{C}$ and part of the projects at grade $\mathrm{D}$. The projects at grade $\mathrm{A}$ include the project set --- $X_{A}$ in unit $X$, the project set --- $Y_{A}$ in unit $Y$ and the project set --- $Z_{A}$ in unit $Z$; at grades $\mathrm{B}$ and $\mathrm{C}$ there is the similar distribution of projects and the three units all have projects at grades B and C. At grade D, only part of the projects can be executed. The projects ranked at the top level and obtaining the budget are respectively from the three units. With the application of the budget allocation model, we can know that the budget unit $X$ gets is $E B_{X}$, unit $Y E B_{Y}$, and unit $Z E B_{Z}$. The senior manager can govern the budget of $M B$ and he allocates $M B_{X}$ to unit $X, M B_{Y}$ to unit $Y$ and $M B_{Z}$ to unit $Z$.

Based on the budget allocation of public infrastructure projects $\left(E B_{X}, E B_{Y}, E B_{Z}\right)$ and the budget allocation from the senior manager $\left(M B_{X}, M B_{Y}, M B_{Z}\right)$, we can work out the budget of each unit $\left(B_{X}, B_{Y}, B_{Z}\right)$.

\section{NUMERICAL EXAMPLE}

\section{Explanation of Decision-making Problem}

It is assumed that the Ministry of Communications is composed of five units which are respectively symbolized with A, $\mathrm{B}, \mathrm{C}, \mathrm{D}, \mathrm{E}$; they submit a total of 22 infrastructure projects in a fiscal year, including 4 from A, 5 from B, 3 from C, 6 from D, 4 from $\mathrm{E}$; The required budget of each project is listed in Table 1. Although the total budgets these proposed projects amounts to NT\$91.44 billion, the actual budget that is available that year is not more than NT $\$ 60$ billion. In this situation, the ministry is faced with the decision-making problem of how to
Table 1. The number of projects and the respective proposed budgets submitted by five units affiliated to the ministry of communications.

\begin{tabular}{ccc}
\hline Unit & Number of Projects & Budget (One-hundred Million NT\$) \\
\hline A & 4 & 179.8 \\
B & 5 & 183.7 \\
C & 3 & 100.9 \\
D & 6 & 284.0 \\
E & 4 & 166.0 \\
\hline Total & 22 & 914.4 \\
\hline
\end{tabular}

Table 2. The evaluation criteria and the weights of public infrastructure projects under the ministry of communications.

\begin{tabular}{|c|c|c|c|c|c|}
\hline $\begin{array}{l}\text { Evaluation } \\
\text { Dimension }\end{array}$ & $\begin{array}{c}\text { Evaluation } \\
\text { Criteria }\end{array}$ & $\begin{array}{l}\text { Criteria } \\
\text { Weights }\end{array}$ & $\begin{array}{l}\text { Evaluation } \\
\text { Dimension }\end{array}$ & $\begin{array}{c}\text { Evaluation } \\
\text { Criteria }\end{array}$ & $\begin{array}{l}\text { Criteria } \\
\text { Weights }\end{array}$ \\
\hline \multirow[t]{5}{*}{$\mathrm{D}_{1}$} & & 0.23 & $\mathrm{D}_{3}$ & $\mathrm{C}_{11}$ & 0.04 \\
\hline & $\mathrm{C}_{1}$ & 0.04 & & $\mathrm{C}_{12}$ & 0.02 \\
\hline & $\mathrm{C}_{2}$ & 0.04 & $\mathrm{D}_{4}$ & & 0.10 \\
\hline & $\mathrm{C}_{3}$ & 0.12 & & $\mathrm{C}_{13}$ & 0.05 \\
\hline & $\mathrm{C}_{4}$ & 0.03 & & $\mathrm{C}_{14}$ & 0.05 \\
\hline \multirow[t]{5}{*}{$\mathrm{D}_{2}$} & & 0.25 & $\mathrm{D}_{5}$ & & 0.16 \\
\hline & $\mathrm{C}_{5}$ & 0.07 & & $\mathrm{C}_{15}$ & 0.06 \\
\hline & $\mathrm{C}_{6}$ & 0.07 & & $\mathrm{C}_{16}$ & 0.05 \\
\hline & $\mathrm{C}_{7}$ & 0.04 & & $\mathrm{C}_{17}$ & 0.05 \\
\hline & $\mathrm{C}_{8}$ & 0.07 & $\mathrm{D}_{6}$ & & 0.08 \\
\hline \multirow[t]{2}{*}{$\mathrm{D}_{3}$} & & 0.18 & & $\mathrm{C}_{18}$ & 0.04 \\
\hline & $\mathrm{C}_{9}$ & 0.04 & & $\mathrm{C}_{19}$ & 0.04 \\
\hline
\end{tabular}

allocate the available budget and how to decide which projects ought to be executed.

For the sake of conciseness, the decision-making judgment of experts is illustrated with non-fuzzy numbers in this numerical example.

\section{The Formulation of Evaluation Criteria and the Determination of Weighting}

In order to facilitate the evaluation of budget allocation for the projects submitted by each unit, the Ministry of Communications first formulates a set of evaluation criteria accepted by each unit. The results of the investigation and analysis undertaken by this ministry indicate that these criteria consist of 6 evaluation dimensions and 19 evaluation indices. In terms of weighting, the calculation is performed on the basis that the total weight is 1 . The details are shown in Table 2.

In order to simplify the evaluation work, the ministry decides to adopt the fuzzy multi-criteria grade classification model to classify the infrastructure projects into different grades in light of their need priorities. An evaluation committee with 8 members is constituted, including people recommended by each unit, guest experts and scholars; these 
Table 3. Results of the evaluation made by experts on $\mathbf{A}_{11}$.

\begin{tabular}{ccccccc}
\hline \multirow{2}{*}{ Evaluation Dimension } & \multirow{2}{*}{ Evaluation Criteria } & \multicolumn{5}{c}{ The Need Grades of Infrastructure Projects } \\
\cline { 3 - 6 } & & Urgently needed & Greatly needed & Very needed & Fairly needed & Slightly needed \\
\hline $\mathrm{D}_{1}$ & $\mathrm{C}_{1}$ & 2 & 3 & 1 & 1 & 1 \\
& $\mathrm{C}_{2}$ & 3 & 1 & 2 & 2 & 0 \\
& $\mathrm{C}_{3}$ & 3 & 2 & 2 & 0 & 1 \\
& $\mathrm{C}_{4}$ & 2 & 3 & 1 & 2 & 0 \\
\hline $\mathrm{D}_{2}$ & $\mathrm{C}_{5}$ & 1 & 2 & 3 & 1 & 1 \\
& $\mathrm{C}_{6}$ & 2 & 2 & 2 & 1 & 1 \\
& $\mathrm{C}_{7}$ & 1 & 1 & 2 & 3 & 1 \\
& $\mathrm{C}_{8}$ & 3 & 2 & 1 & 2 & 0 \\
\hline $\mathrm{D}_{3}$ & $\mathrm{C}_{9}$ & 2 & 2 & 1 & 1 & 2 \\
& $\mathrm{C}_{10}$ & 1 & 3 & 2 & 1 & 1 \\
& $\mathrm{C}_{11}$ & 2 & 2 & 2 & 1 & 1 \\
\hline $\mathrm{C}_{12}$ & 1 & 2 & 3 & 0 & 1 \\
\hline $\mathrm{D}_{4}$ & $\mathrm{C}_{13}$ & 2 & 4 & 0 & 1 & 1 \\
\hline $\mathrm{C}_{5}$ & $\mathrm{C}_{14}$ & 2 & 2 & 3 & 0 & 0 \\
& $\mathrm{C}_{15}$ & 1 & 3 & 2 & 2 & 1 \\
\hline & $\mathrm{C}_{16}$ & 2 & 2 & 3 & 1 & 1 \\
\hline $\mathrm{C}_{6}$ & $\mathrm{C}_{17}$ & 1 & 3 & 1 & 2 & 1 \\
\hline
\end{tabular}

evaluation members will make their judgments based on the need priorities of projects under the 19 evaluation criteria and check the grade that they think is appropriate, according to the prospectus, field surveys and briefings submitted by each unit.

\section{Grade Classification of the Need Priority of Infrastructure Projects}

In terms of need priority, the infrastructure projects are classified by the Ministry of Communications into 5 grades: "urgently needed", "greatly needed", "very needed", "fairly needed" and "slightly needed".

The infrastructure project $A_{11}$, submitted by unit $\mathrm{A}$, is taken as an instance, and the evaluation results of the eight members are shown in Table 3, in which the numbers are the comprehensive judgments made by the eight members. If the evaluation results from the eight members are expressed with numerical values totalling 1 , as Table 4 shows, the comprehensive judgment of the eight members on $A_{11}$, for example, is that under the criterion --- $C_{1}$, this project belongs to the grade of "greatly needed" --- 0.375 ; the second highest is "urgently needed" (the degree of membership is 0.250 ). Then according to the weights under the 19 criteria and the need degrees of membership for each grade, we can obtain the comprehensive degrees of membership for each grade: $0.244,0.285,0.228$, $0.143,0.101$. It can be seen that the comprehensive degree of membership of the grade "greatly needed" is still the highest.

If these eight members determine the grades of the projects on the premise of $\lambda=0.5$, the accumulated degree of membership at the second grade is 0.529 , exceeding the value of $\lambda$. Therefore, $A_{11}$ belongs to the grade of "greatly needed," ac- cording to the comprehensive evaluation results.

The comprehensive evaluation and classification results of all projects submitted by the five units from the eight evaluation members are detailed in Table 5: there are altogether five infrastructure projects at the grade of "urgently needed," another five projects at the grade of "greatly needed," seven projects at the grade of "very needed," four projects at the grade of "fairly needed" and only 1 project at the grade of "slightly needed." Table 5 shows that the total needed budget of projects at each grade is just equal to the total amount of the needed construction budget at this grade. More details are shown in Table 6.

\section{RESULTS AND DISCUSSIONS}

Ministry of Communications decides to allocate the budget according to the evaluation and classification results of the infrastructure projects submitted by each unit. Suppose the total budget of this ministry in this fiscal year is NT $\$ 60$ billion, $10 \%$ of which is dominated by the senior manager and $90 \%$ of which is distributed according as the comprehensive evaluation results of the projects. The principle of allocating the budget of NT $\$ 54$ billion is that the projects at a higher need grade should be given the budget priority.

Table 6, which shows the construction budget needed by the projects at each grade, we can see that when the available budget is only NT \$54 billion, the ten infrastructure projects at the grades of "urgently needed" and "greatly needed" can all be executed in the current year; but at the grade of "very needed," the budget has accumulated to NT\$67.75 billion 
Table 4. Results of the comprehensive evaluation on $A_{11}$.

\begin{tabular}{|c|c|c|c|c|c|c|c|}
\hline \multirow{2}{*}{$\begin{array}{c}\text { Evaluation } \\
\text { Dimension }\left(D_{i}\right)\end{array}$} & \multirow{2}{*}{$\begin{array}{l}\text { Evaluation Criteria } \\
\qquad\left(C_{i}\right)\end{array}$} & \multirow{2}{*}{$\begin{array}{c}\text { Criteria Weight } \\
\left(W_{i}\right)\end{array}$} & \multicolumn{5}{|c|}{ The Classification of Infrastructure Projects According to the Need Priority $\left(V_{k}\right)$} \\
\hline & & & $\begin{array}{l}\text { Urgently needed } \\
\qquad\left(V_{1}\right)\end{array}$ & $\begin{array}{l}\text { Greatly needed } \\
\qquad\left(V_{2}\right)\end{array}$ & $\begin{array}{c}\text { Very needed } \\
\left(V_{3}\right)\end{array}$ & $\begin{array}{c}\text { Fairly needed } \\
\qquad\left(V_{4}\right)\end{array}$ & $\begin{array}{c}\text { Slightly needed } \\
\qquad\left(V_{5}\right)\end{array}$ \\
\hline \multirow[t]{4}{*}{$\mathrm{D}_{1}$} & $\mathrm{C}_{1}$ & 0.04 & 0.250 & 0.375 & 0.125 & 0.125 & 0.125 \\
\hline & $\mathrm{C}_{2}$ & 0.04 & 0.375 & 0.125 & 0.250 & 0.250 & 0.000 \\
\hline & $\mathrm{C}_{3}$ & 0.12 & 0.375 & 0.250 & 0.250 & 0.000 & 0.125 \\
\hline & $\mathrm{C}_{4}$ & 0.03 & 0.250 & 0.375 & 0.125 & 0.250 & 0.000 \\
\hline \multirow[t]{4}{*}{$\mathrm{D}_{2}$} & $\mathrm{C}_{5}$ & 0.07 & 0.125 & 0.250 & 0.375 & 0.125 & 0.125 \\
\hline & $\mathrm{C}_{6}$ & 0.07 & 0.250 & 0.250 & 0.250 & 0.125 & 0.125 \\
\hline & $\mathrm{C}_{7}$ & 0.04 & 0.125 & 0.125 & 0.250 & 0.375 & 0.125 \\
\hline & $\mathrm{C}_{8}$ & 0.07 & 0.375 & 0.250 & 0.125 & 0.250 & 0.000 \\
\hline \multirow[t]{4}{*}{$D_{3}$} & $\mathrm{C}_{9}$ & 0.04 & 0.250 & 0.250 & 0.125 & 0.125 & 0.250 \\
\hline & $\mathrm{C}_{10}$ & 0.08 & 0.125 & 0.375 & 0.250 & 0.125 & 0.125 \\
\hline & $\mathrm{C}_{11}$ & 0.04 & 0.250 & 0.250 & 0.250 & 0.125 & 0.125 \\
\hline & $\mathrm{C}_{12}$ & 0.02 & 0.125 & 0.250 & 0.375 & 0.000 & 0.250 \\
\hline \multirow[t]{2}{*}{$\mathrm{D}_{4}$} & $\mathrm{C}_{13}$ & 0.05 & 0.250 & 0.500 & 0.000 & 0.125 & 0.125 \\
\hline & $\mathrm{C}_{14}$ & 0.05 & 0.250 & 0.250 & 0.375 & 0.000 & 0.125 \\
\hline \multirow[t]{3}{*}{$\mathrm{D}_{5}$} & $\mathrm{C}_{15}$ & 0.06 & 0.125 & 0.375 & 0.250 & 0.250 & 0.000 \\
\hline & $\mathrm{C}_{16}$ & 0.05 & 0.250 & 0.250 & 0.375 & 0.125 & 0.000 \\
\hline & $\mathrm{C}_{17}$ & 0.05 & 0.125 & 0.375 & 0.125 & 0.250 & 0.125 \\
\hline \multirow[t]{2}{*}{$\mathrm{D}_{6}$} & $\mathrm{C}_{18}$ & 0.04 & 0.250 & 0.250 & 0.250 & 0.125 & 0.125 \\
\hline & $\mathrm{C}_{19}$ & 0.04 & 0.375 & 0.250 & 0.125 & 0.125 & 0.125 \\
\hline \multicolumn{3}{|c|}{$\begin{array}{l}\text { The degrees of membership of } \\
\text { comprehensive evaluation for each grade }\end{array}$} & 0.244 & 0.285 & 0.228 & 0.143 & 0.101 \\
\hline \multicolumn{3}{|c|}{$\begin{array}{l}\text { Accumulated values of the degree of } \\
\text { membership for each grade }\end{array}$} & 0.244 & 0.529 & 0.757 & 0.899 & 1.000 \\
\hline
\end{tabular}

Table 5. Results of evaluation on infrastructure projects submitted by each unit.

\begin{tabular}{|c|c|c|c|c|c|c|c|c|}
\hline \multirow[t]{2}{*}{ Units $\left(s_{i}\right)$} & \multirow[t]{2}{*}{ Projects $\left(A_{s i}\right)$} & \multicolumn{5}{|c|}{ The Degrees of Need for Projects $(k)$} & \multirow[t]{2}{*}{ Grade $\left(V_{k}\right)$} & \multirow{2}{*}{$\begin{array}{l}\text { Needed Construction Budget } \\
\text { (One-hundred Million NT\$) }\end{array}$} \\
\hline & & $V_{1}$ & $V_{2}$ & $V_{3}$ & $V_{4}$ & $V_{5}$ & & \\
\hline \multirow[t]{4}{*}{$\mathrm{A}\left(s_{1}\right)$} & $\mathrm{A}_{11}$ & 0.244 & 0.285 & 0.228 & 0.143 & 0.101 & $\mathrm{~V}_{2}$ & 43.8 \\
\hline & $\mathrm{A}_{12}$ & 0.514 & 0.188 & 0.126 & 0.102 & 0.070 & $\mathrm{~V}_{1}$ & 33.6 \\
\hline & $\mathrm{A}_{13}$ & 0.153 & 0.265 & 0.260 & 0.200 & 0.122 & $\mathrm{~V}_{3}$ & 54.4 \\
\hline & $\mathrm{A}_{14}$ & 0.086 & 0.126 & 0.288 & 0.312 & 0.248 & $\mathrm{~V}_{4}$ & 48.0 \\
\hline \multirow[t]{5}{*}{$\mathrm{B}\left(s_{2}\right)$} & $\mathrm{A}_{21}$ & 0.432 & 0.316 & 0.124 & 0.106 & 0.022 & $\mathrm{~V}_{2}$ & 27.3 \\
\hline & $\mathrm{A}_{22}$ & 0.105 & 0.246 & 0.188 & 0.248 & 0.213 & $\mathrm{~V}_{3}$ & 41.0 \\
\hline & $\mathrm{A}_{23}$ & 0.211 & 0.128 & 0.256 & 0.190 & 0.215 & $\mathrm{~V}_{3}$ & 29.2 \\
\hline & $\mathrm{A}_{24}$ & 0.086 & 0.463 & 0.318 & 0.097 & 0.036 & $\mathrm{v}_{2}$ & 38.7 \\
\hline & $\mathrm{A}_{25}$ & 0.202 & 0.216 & 0.248 & 0.198 & 0.136 & $\mathrm{~V}_{3}$ & 47.5 \\
\hline \multirow[t]{3}{*}{$\mathrm{C}\left(s_{3}\right)$} & $\mathrm{A}_{31}$ & 0.382 & 0.214 & 0.121 & 0.182 & 0.101 & $\mathrm{~V}_{2}$ & 27.3 \\
\hline & $\mathrm{A}_{32}$ & 0.120 & 0.152 & 0.239 & 0.224 & 0.265 & $\mathrm{~V}_{3}$ & 30.8 \\
\hline & $\mathrm{A}_{33}$ & 0.514 & 0.188 & 0.126 & 0.102 & 0.070 & $\mathrm{~V}_{1}$ & 42.8 \\
\hline \multirow[t]{6}{*}{$\mathrm{D}\left(s_{4}\right)$} & $\mathrm{A}_{41}$ & 0.032 & 0.094 & 0.118 & 0.132 & 0.624 & $\mathrm{~V}_{5}$ & 63.0 \\
\hline & $\mathrm{A}_{42}$ & 0.076 & 0.114 & 0.282 & 0.388 & 0.140 & $\mathrm{~V}_{4}$ & 39.7 \\
\hline & $\mathrm{A}_{43}$ & 0.110 & 0.168 & 0.256 & 0.242 & 0.124 & $\mathrm{~V}_{3}$ & 37.8 \\
\hline & $\mathrm{A}_{44}$ & 0.632 & 0.206 & 0.102 & 0.042 & 0.018 & $\mathrm{~V}_{1}$ & 44.8 \\
\hline & $\mathrm{A}_{45}$ & 0.584 & 0.106 & 0.214 & 0.082 & 0.014 & $\mathrm{~V}_{1}$ & 51.4 \\
\hline & $\mathrm{A}_{46}$ & 0.128 & 0.266 & 0.284 & 0.168 & 0.154 & $\mathrm{~V}_{3}$ & 47.3 \\
\hline \multirow[t]{4}{*}{$\mathrm{E}\left(s_{5}\right)$} & $\mathrm{A}_{51}$ & 0.112 & 0.125 & 0.146 & 0.357 & 0.260 & $\mathrm{~V}_{4}$ & 48.2 \\
\hline & $\mathrm{A}_{52}$ & 0.262 & 0.305 & 0.186 & 0.139 & 0.108 & $\mathrm{~V}_{2}$ & 27.8 \\
\hline & $\mathrm{A}_{53}$ & 0.628 & 0.116 & 0.108 & 0.102 & 0.046 & $\mathrm{~V}_{1}$ & 52.0 \\
\hline & $\mathrm{A}_{54}$ & 0.102 & 0.124 & 0.206 & 0.262 & 0.306 & $\mathrm{~V}_{4}$ & 38.0 \\
\hline
\end{tabular}


Table 6. The infrastructure projects and the needed budget at each grade.

\begin{tabular}{llcc}
\hline $\begin{array}{l}\text { Need Grades } \\
\left(V_{k}\right)\end{array}$ & \multicolumn{1}{c}{\begin{tabular}{c}
\multicolumn{1}{c}{$\begin{array}{c}\text { Projects } \\
\left(A_{s i}\right)\end{array}$} \\
Urgently needed $\left(V_{1}\right)$
\end{tabular}} & $\begin{array}{c}\text { Needed Construction Budget } \\
\text { (One-hundred Million NT\$) }\end{array}$ & $\begin{array}{c}\text { Accumulated Construction Budget } \\
\text { (One-hundred Million NT\$) }\end{array}$ \\
Greatly needed $\left(V_{2}\right)$ & $\mathrm{A}_{12}, \mathrm{~A}_{33}, \mathrm{~A}_{44}, \mathrm{~A}_{45}, \mathrm{~A}_{53}$ & 224.6 & 224.6 \\
Very needed $\left(V_{3}\right)$ & $\mathrm{A}_{13}, \mathrm{~A}_{21}, \mathrm{~A}_{24}, \mathrm{~A}_{23}, \mathrm{~A}_{25}, \mathrm{~A}_{52}, \mathrm{~A}_{43}, \mathrm{~A}_{46}$ & 164.9 & 389.5 \\
Fairly needed $\left(V_{4}\right)$ & $\mathrm{A}_{14}, \mathrm{~A}_{42}, \mathrm{~A}_{51}, \mathrm{~A}_{54}$ & 288.0 & 677.5 \\
Slightly needed $\left(V_{5}\right)$ & $\mathrm{A}_{41}$ & 173.9 & 851.4 \\
\hline
\end{tabular}

Table 7. The ranking of projects at the grade of "very needed $\left(V_{3}\right)$ ".

\begin{tabular}{ccccc}
\hline Level & Projects $\left(A_{s i}\right)$ & Average Weighted Scores & $\begin{array}{c}\text { Needed Construction Budget } \\
\text { (One-hundred Million NT\$) }\end{array}$ & $\begin{array}{c}\text { Accumulated Construction Budget } \\
\text { (One-hundred Million NT\$) }\end{array}$ \\
\hline 1 & $\mathrm{~A}_{25}$ & 72.4 & 47.5 & 47.5 \\
2 & $\mathrm{~A}_{13}$ & 68.2 & 54.4 & 101.9 \\
3 & $\mathrm{~A}_{46}$ & 66.6 & 47.3 & 149.2 \\
4 & $\mathrm{~A}_{23}$ & 62.7 & 29.2 & 178.4 \\
5 & $\mathrm{~A}_{22}$ & 58.6 & 41.0 & 219.4 \\
6 & $\mathrm{~A}_{32}$ & 53.5 & 30.8 & 250.2 \\
7 & $\mathrm{~A}_{43}$ & 48.8 & 37.8 & 288.0 \\
\hline
\end{tabular}

Table 8. The budget dominated by the senior manager and its allocation.

\begin{tabular}{ccc}
\hline Units $\left(S_{i}\right)$ & $\begin{array}{c}\text { Projects with the } \\
\text { Budget Allocation }\left(A_{s i}\right)\end{array}$ & $\begin{array}{c}\text { Needed Construction Budget } \\
\text { (One-hundred Million NT\$) }\end{array}$ \\
\hline $\mathrm{B}\left(S_{2}\right)$ & $A_{23}$ & 29.2 \\
$\mathrm{C}\left(S_{3}\right)$ & $A_{32}$ & 30.8 \\
\hline \multicolumn{2}{c}{ Total Budget Dominated by } \\
the Senior Manager
\end{tabular}

which exceeds NT\$54 billion. Therefore, the projects at the third grade can only get NT $\$ 15.05$ billion after the budget given to those at the first and second grades is deducted; however, the seven projects at the third grade need a total budget of NT\$28.8 billion and there is a shortage of NT\$13.75 billion. For this reason, the seven projects at the grade of "very needed" must be ranked.

Based on the fuzzy multi-criteria project ranking model proposed by this paper, the evaluation members decide to utilize the scoring method to evaluate and calculate the weighted scores of the seven infrastructure projects. The evaluation members apply the 100-point system to compute the average scores, which the seven projects can respectively get, and then these projects are ranked according to the descending order of the average scores, as Table 7 shows; then the rest of NT\$15.05 billion is allocated to the projects from a high to low. Table 7 indicates that after the project at the third ranking level, the budget has been used up. Therefore, except for those that must be considered by the senior manager, the four projects under the third ranking level and the five ones at the grades of "fairly needed" and "slightly needed" all cannot be executed due to lack of money.
Table 9. The budget allocation results of the approved infrastructure projects from each unit.

\begin{tabular}{lcc}
\hline Units $\left(S_{i}\right)$ & Executable Projects $\left(A_{s i}\right)$ & $\begin{array}{c}\text { Budget Allocation } \\
\text { (One-hundred Million NT\$) }\end{array}$ \\
\hline $\mathrm{A}\left(S_{1}\right)$ & $\mathrm{A}_{11}, \mathrm{~A}_{12}, \mathrm{~A}_{13}$ & 131.8 \\
$\mathrm{~B}\left(S_{2}\right)$ & $\mathrm{A}_{21}, \mathrm{~A}_{23}, \mathrm{~A}_{24}, \mathrm{~A}_{25}$ & 142.7 \\
$\mathrm{C}\left(S_{3}\right)$ & $\mathrm{A}_{31}, \mathrm{~A}_{32}, \mathrm{~A}_{33}$ & 100.9 \\
$\mathrm{D}\left(S_{4}\right)$ & $\mathrm{A}_{44}, \mathrm{~A}_{45}, \mathrm{~A}_{46}$ & 143.5 \\
$\mathrm{E}\left(S_{5}\right)$ & $\mathrm{A}_{52}, \mathrm{~A}_{53}$ & 79.8 \\
\hline Total & & $598.7 \leq 600(\mathrm{OK})$. \\
\hline
\end{tabular}

Within the budget of NT $\$ 6$ billion that the senior manager can dominate, it is assumed that the senior manager decides to respectively give Unit $\mathrm{B}$ and Unit $\mathrm{C}$ a project, and the results are shown in Table 8.

According as the results of the evaluation and budget allocation for the infrastructure projects submitted by the five units in this ministry, we can know the construction budget of each unit in this fiscal year by calculating the needed budget of executable projects chosen out from each unit at each grade, as Table 9 shows. It can also be seen that unit A can be allocated NT\$13.18 billion, unit C NT\$10.09 billion and unit D NT $\$ 14.35$ billion, and there are respectively three projects from these three units to be executed; unit E is given NT\$7.98 billion and there are two projects from it to be implemented; unit B gets NT $\$ 14.27$ billion and there are altogether four projects from it to be considered.

Therefore, among the 22 infrastructure projects submitted by the five units from Ministry of Communications, there are altogether 15 projects to be executed with the total construction budget of NT\$59.87 billion. 
The budget allocation model of public infrastructure projects advanced in this paper can easily meet the changing demands of response policies to check the objective adjustments for the projects. For instance, if the total budget is cut down from NT\$60 billion to NT\$55 billion, the available budget is reduced by NT $\$ 5$ billion. Suppose the budget dominated by the senior manager is still NT $\$ 6$ billion, one project at the lowest ranking level of the third grade can be deleted; if more budget is cut, the deletion proceeds upwards along the ranking order. When all projects at the third grade are eliminated, it is the turn of the projects at the second grade to be removed after they are ranked; likewise, the project at the lowest ranking level of this grade needs to be omitted first. Thus, the limited budget can be effectively allocated.

\section{CONCLUSIONS}

The evaluation and selection of public infrastructure projects are conducted according to multi-person and multi-criteria principles. In evaluating and selecting projects, we have to take into account not only the cost, the society, finance, markets, the environment, politics and management but also the methods by which to evaluate projects, choose the members on the evaluation committee, decide the size of the committee, and meet the demands of the fuzzy scale. What matters most is how to realize the optimal allocation of limited budgets via the evaluation of infrastructure projects.

Due to the multitude of the infrastructure projects and the units submitting projects and the diversity in specialties, it is a huge burden on the evaluation members, whatever classified or collective evaluation is adopted. This study combines fuzzy theory and multi-criteria evaluation method to propose the fuzzy multi-criteria grade classification model. The evaluation members can make judgments and choices according to the evaluation criteria and the need priority of projects to greatly simplify the evaluation work.

When not all projects at the same grade can receive funding, the principle of allocation is to consider first those with high need priorities. This study combines the widely-used scoring method and multicriteria property to come up with the fuzzy multi-criteria project ranking model that can be utilized to evaluate the need levels of the projects at the same grade.

The proposed budget allocation model of public infrastructure projects can simultaneously distribute the budget of public infrastructure projects and the construction budgets for each unit. This model integrates 3 sub-models--- the fuzzy multicriteria grade classification model, the fuzzy multi-criteria project ranking model and the budget allocation model. The budget allocation methods proposed in this paper can easily meet the changing demands of response budget policies. When budgets need to be reduced or increased, we can quickly decide in which units and of which projects of each particular budget should be reduced or increased.

Except to integrate the need and multi-criteria evaluation properties of projects, the budget allocation methods men- tioned in this paper also take it into consideration that the senior manager should have the right to use a certain proportion of the budget, in order to give him or her the same rights and responsibilities. Thus, the senior manager can significantly improve management efficiency and take the corresponding responsibility. The senior manager cannot govern without a budget, but he or she is not allowed to dominate too much of it; the proportion of budget he or she governs should be decided by laws and regulations.

The evaluation of infrastructure projects can be examined according to different categories, but the number, qualification and candidates of the evaluation members have to be chosen from the personnel file; meanwhile, the invited members must have professional knowledge related to the project of this kind, otherwise, they cannot make any judgments. The number of evaluation members depends on the amount of the budget, namely, the more budget there is, the more members there are; on the contrary, the less budget there is, the fewer members there are. In selecting evaluation members, it is necessary to consider the balance between each group.

The evaluation criteria of public infrastructure projects will have to be timely adjusted with the continuous changes of time and outside circumstances; the modification of these criteria must be discussed by scholars from related units to achieve a generally-accepted scheme. Furthermore, the evaluation system of the senior units will be faced with a large difference in specialty; thus, it is a serious challenge to formulate a sufficiently sensitive evaluation criterion.

\section{ACKNOWLEDGMENTS}

The authors would like to express their gratitude for the detailed attention and valuable feedback from the referees, and the suggestions and encouragement from the Editor during the review period.

\section{REFERENCES}

1. Al-Subhi Al-Harbi, K. M., "Application of the AHP in project management," International Journal of Project Management, Vol. 19, No. 1, pp. 19-27 (2001).

2. Azis, I. J., "Analytic hierarchy process in the benefit-cost framework: A post-evaluation of the Trans-Sumatra highway project," European of $\mathrm{Op}$ erational Research, Vol. 48, pp. 38-48 (1990).

3. Baas, S. M. and Kwakernaak, H., "Rating and ranking of multiple aspect alternative using fuzzy sets," Automatica, Vol. 13, No. 1, pp. 47-58 (1977).

4. Belenky, V. Z. and Belostotsky, A. M., "Resource allocation and project selection: Control of R\&D under dynamic process of data improvement," Theory and Decision, Vol. 26, No. 1, pp. 1-35 (1989).

5. Bellman, R. E. and Zadeh, L. A., "Decision-making in a fuzzy environment," Management Science, Vol. 17, No. 4, pp. 141-164 (1970).

6. Booker, J. M. and Bryson, M. C., "Decision analysis in project management: An overview," IEEE Transactions on Engineering Management, Vol. 32, No. 1, pp. 3-9 (1985).

7. Buckley, J. J., "Fuzzy hierarchical analysis," Fuzzy Sets and Systems, Vol. 17, No. 1, pp. 233-247 (1985).

8. Chen, S. J. and Hwang, C. L., Fuzzy Multiple Attribute Decision Making, Methods and Applications, in: Lecture Notes in Economics and Mathe- 
matical Systems, Vol. 375, Springer, New York (1993)

9. Cook, T., Falchi, P., and Mariano, R., "An urban allocation model combining time series and analytic hierarchical methods," Management Science, Vol. 30, No. 2, pp. 198-208 (1984).

10. Davies, G. B. and Pearson, A. W., "The application of some group problemsolving approaches to project selection in research and development,' IEEE Transactions on Engineering Management, Vol. EM-27, No. 3, pp. 66-73 (1980).

11. Fong, S. W. and Choi, S. K. Y., "Final contractor selection using the analytical hierarchy process," Construction Management and Economics, Vol. 18, No. 5, pp. 547-557 (2000).

12. Gear, A. E., Lackett, A. G., and Pearson, A. W., "Analysis of some portfolio selection models for R\&D," IEEE Transactions on Engineering Management, Vol. EM-18, No. 2, pp. 66-76 (1971).

13. Han, Y., Wu, X., and Yue, C., "Optimizing financial budget for software implementation based on the development effort and cost function," Advances in Engineering Software, Vol. 36, Issue 10, pp. 699-706 (2005).

14. Hsinng, J. and Tsaur, K. S., "An addition of grade classification," The Theses of Management and Systems Science, Vol. 1, pp. 298-303 (1991). [in Chinese]

15. Hsu, Y. G., Tzeng, G. H. and Shyu, J. Z., "Fuzzy multiple criteria selection of government-sponsored frontier technology R\&D projects," $R \& D$ Management, Vol. 33, No. 5, pp. 539-551 (2003).

16. Johnstone, D. J., "The value of a probability forecast from portfolio theory," Theory and Decision, Vol. 63, No. 2, pp. 153-203 (2007).

17. Karydas, D. M. and Gifun, J. F., "A method for the efficient prioritization of infrastructure renewal projects," Reliability Engineering \& System Safety, Vol. 91, Issue 1, pp. 84-99 (2006).

18. Kwak, N. K. and Diminnie, C. B., "A programming model for allocating operating budgets of academic units," Socio-Economic Planning Sciences, Vol. 21, No. 5, pp. 333-339 (1987).

19. Lee, K. L., Huang, W. C., and Teng, J. Y., "Locating the competitive relation of global logistics hub using quantitative SWOT analytical method," Quality and Quantity, http://www.springerlink.com, published online: 29 March (2007).

20. Mahdi, I. M., Riley, M. J., Fereig, S. M., and Alex, A. P., "A multi-criteria approach to contractor selection," Engineering Construction and Architectural Management, Vol. 9, No. 1, pp. 29-37 (2002).

21. McIntyre, C. and Parfitt, M. K., "Decision support system for residential land development site selection process," Journal of Architectural Engineering, ASCE, Vol. 4, No. 4, pp. 125-131 (1998).
22. Pearman, A. D., Mackie, P. J., May, A. D., and Simon, D., The Use of Multi-Criteria Techniques to Rank Highway Investment Proposals, in Improving Decision Making in Organisations, Lockett, A. G. and Islei, G. (eds.), Springer Verlag, Berlin (1989).

23. Perng, Y. H., Juan, Y. K., and Hsu, H. S., "Genetic algorithm-based decision support for the restoration budget allocation of historical buildings," Building and Environment, Vol. 42, pp. 770-778 (2007).

24. Ramanathan, R. and Ganesh, L. S., "Using AHP for resource allocation problems," European Journal of Operational Research, Vol. 80, pp. 410417 (1995).

25. Schroder, H. H., "R\&D project evaluation and selection models for development: A survey of the state of the art," Socio-Economic Planning Sciences, Vol. 5, No. 1, pp. 25-39 (1971).

26. Tang, M. T., Tzeng, G. H., and Wang, S. W., “A hierarchy fuzzy MCDM method for studying electronic marketing strategies in the information service industry," Journal of International Information Management, Vol. 8, No. 1, pp. 1-22 (1999).

27. Teng J. Y. and Tzeng, G. H., "Fuzzy multicriteria ranking of urban transportation investment alternatives," Transportation Planning and Technology, Vol. 20, No. 1, pp. 15-31 (1996).

28. Teng, J. Y., Yeh, R. C., Lin, M. C., and Huang, W. C., "The budget allocation of transportation construction projects by fuzzy multicriteria grade classification model," Journal of the Eastern Asia Society for Transportation Studies, Vol. 7, pp. 415-426 (2007).

29. Tsai, M. T., Wu, H. L., and Liang, W. K., "Fuzzy decision making for market positioning and developing strategy for improving service quality in department stores," Quality and Quantity, http://www.springerlink. com, published online: 14 September (2006).

30. Tsaur, S. H., Tzeng, G. H., and Wang, G. C., "Evaluating tourist risks from fuzzy perspectives," Annals of Tourism Research, Vol. 24, No. 4, pp. 796812 (1997).

31. Tzeng, G. H., Shiah, T. A., and Teng, J. Y., "A multiobjective decision making approach to energy supply mix decisions in Taiwan," Energy Sources, Vol. 16, No. 3, pp. 301-316 (1994).

32. Weber, R., Werners, B., and Zimmermann, H. J., "Planning models for research and development," European Journal of Operational Research, Vol. 48, pp. 175-188 (1990).

33. Wu, C. R., Lin, C. T., and Chen, H. C., "Integrated environmental assessment of the location selection with fuzzy analytical network process," Quality and Quantity, http://www.springerlink.com, published online: 22 September (2007). 